\title{
In Vitro Chloroquine Resistance Modulation Study on Fresh Isolates of Brazilian Plasmodium falciparum: Intrinsic Antimalarial Activity of Phenothiazine Drugs
}

\author{
Carla MS Menezes, Karin Kirchgatter*, Sílvia M Di Santi*, Carine Savalli**, \\ Fabiola G Monteiro ${ }^{* *}$, Gilberto A Paula**, Elizabeth I Ferreira/ ${ }^{+}$
}

Faculdade de Ciências Farmacêuticas **Instituto de Matemática e Estatística, Universidade de São Paulo, Av. Prof. Lineu Prestes 580, B1. 13, 05508-900 São Paulo, SP, Brasil *Divisão de Programas Especiais, Superintendência de Controle de Endemias, São Paulo, SP, Brasil

Phenothiazine drugs - fluphenazine, chlorpromazine, methotrimeprazine and trifluoperazine - were evaluated as modulating agents against Brazilian chloroquine-resistant fresh isolates of Plasmodium falciparum. Aiming to simulate therapeutic schedules, chloroquine was employed at the concentration used for sensitive falciparum malaria treatment and anti-psychotic therapeutic concentrations of the phenothiazine drugs were adopted in two-fold serial dilutions. The in vitro microtechnique for drug susceptibility was employed. Unlike earlier reported data, the phenothiazine modulating effect was not observed. However, all the drugs demonstrated intrinsic antiplasmodial activity in concentrations lower than those described in the literature. In addition, $I C_{50}$ estimates have been shown to be inferior to the usual anti-psychotic therapeutic concentrations. Statistical analysis also suggested an increase in the parasitaemia rate or, even, a predominant antiparasitic effect of phenothiazine over chloroquine when used in combination.

Key words: antimalarial - chloroquine - multidrug resistance - phenothiazines - modulating agents - chemosensitizer agents

The global situation of malaria is claiming attention more than ever. It has been estimated that about 300 million acute clinical cases are reported each year, with at least one million deaths (WHO 2000). Antimalarial drug resistance is among the principal factors responsible for this serious public health problem. Resistance has been associated with the parasite's natural biological mechanisms in response to uncontrolled and unregulated drug distribution programs, resulting in genetic mutations (Wellems \& Plowe 2001).

Many efforts have been made in the search for a new and effective antimalarial agent. However, little success has been achieved and, therefore, the restoration of current available drugs becomes an important alternative. Combination therapy is particularly studied concerning chloroquine (Fig. 1), although the major Plasmodium falciparum strains and the emergent $P$. vivax are resistant, this drug remains the most important antimalarial agent. Good pharmacokinectic features, easy use and low cost are its principal properties (Ward \& Bray 2001).

With the purpose of restoring chloroquine efficacy and considering the reported reversal effect of tricyclic drugs on resistant malaria (Bitonti et al. 1988, Basco \& Le Bras 1990, 1991, Kyle et al. 1990, 1993, Peters et al. 1990, Basco \& Le Bras 1992, Miki et al. 1992, Oduola et al. 1998),

Financial support: $\mathrm{CNPq}$

${ }^{+}$Corresponding author. Fax: +55-11-3815-4418. E-mail: hajudan@usp.br

Received 8 March 2002

Accepted 15 August 2002 we evaluated the potential effect of the phenothiazine drugs - fluphenazine, chlorpromazine, methotrimeprazine and trifluoperazine (Fig. 1) -, on modulating the chloroquine resistance of Brazilian P. falciparum fresh isolates.

\section{MATERIALS AND METHODS}

The drugs used were chloroquine diphosphate (Fundação para o Remédio Popular), chlorpromazine hydrochloride, fluphenazine dihydrochloride and methotrimeprazine maleate (Cristália Produtos Químicos e Farmacêuticos Ltda.), and trifluoperazine dihydrochloride (SmithKline Beecham).

Two fresh isolates of $P$. falciparum were used: Isolate 1 (Sucen 198/94) and Isolate 2 (Sucen 206/94). Isolate 1 was collected from a 37-year-old woman in her third infection $\left(6,600\right.$ asexual parasites per $\left.\mathrm{mm}^{3}\right)$ and Isolate 2 from a 21 year-old-man in his second infection (7,500 asexual parasites per $\mathrm{mm}^{3}$ ). The infections occurred in the North of Brazil and the individuals had not been submitted to antimalarial treatment in the previous 28 days (BruceChwatt 1986). Blood samples were collected after formal consent from the patients.

Assays were performed in microplates with 96 flatbottomed wells. The culture medium was RPMI-1640, HEPES buffer, gentamicine sulphate, glucose, hypoxanthine, sodium bicarbonate and human type A serum.

The statistical analysis was carried out using the software S-Plus, version 4.5, and the Microsoft Excel for Windows, version 5.0.

In vitro assays - The biological assays were carried out based on the in vitro microtechnique for drug susceptibility (Rieckmann et al. 1978). The microplates were titrated with two-fold serial dilutions of fluphenazine (0.06$4 \mu \mathrm{g} / \mathrm{l})$, chlorpromazine $(3.75-240 \mu \mathrm{g} / \mathrm{l})$, methotrimeprazine 
<smiles>OCCN1CCN(CCCN2c3ccccc3Sc3ccc(C(F)(F)F)cc32)CC1</smiles>

Fluphenazine

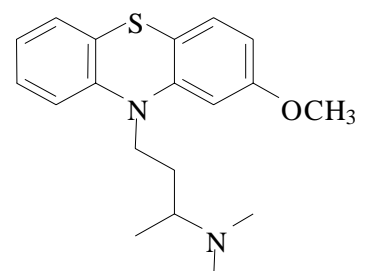

Methotrimeprazine<smiles>CCN(CC)CCCC(C)Nc1ccnc2cc(Cl)ccc12</smiles>

Chloroquine

Fig. 1: chemical structures of the phenothiazines and chloroquine.

$(5-320 \mu \mathrm{g} / \mathrm{l})$, and trifluoperazine $(0.31-20 \mu \mathrm{g} / \mathrm{l})$. In each series, the intermediate value corresponded to the usual antipsychotic therapeutic concentration (Clarke 1986, Benet et al. 1996). Chloroquine $(30 \mu \mathrm{g} / \mathrm{l})$ was added along the series (Tracy \& Webster 1996). The phenothiazine series were also assayed alone with the purpose of evaluating the intrinsic antiplasmodial effect. The chloroquine susceptibility was tested in a range from 3.75 to $240 \mu \mathrm{g} / \mathrm{l}$.

A $10 \%$ haematocrit solution of infected blood was added to the plates. These were incubated according to the candle jar method (Trager \& Jensen 1976) at $37^{\circ} \mathrm{C}$ for $40 \mathrm{~h}$ (Isolate 1) and for $46 \mathrm{~h}$ (Isolate 2). Schizonts with three or more nuclei in 200 parasites were counted.

Statistical analysis - Lines for the parasitaemia rate number of parasites in each concentration/number of parasites in the control - as a function of the chloroquine and phenothiazine drug concentrations and the respective combinations with chloroquine were constructed and submitted to descriptive and inferential analyses (Breslow \&
Day 1980, Collett 1991). Linear and quadratic logistic models and the log-log complement model were considered. According to these, coincident and separated, parallel and concurrent (one or two intercepts) lines were fitted. The $10 \%$ significance level was adopted for the likelihood ratio statistic which, in this case, corresponds to the difference between two goodness-of-fit statistics. In addition, the $50 \%$ inhibitory concentration, $\mathrm{IC}_{50}$, of each drug and its combination with chloroquine was estimated.

\section{RESULTS}

The susceptibility of the isolates to chloroquine, phenothiazine drugs and their combinations can be seen in the descriptive analysis lines (Figs 2 to 6 show the lines calculated for Isolate 1). A decrease in the parasitaemia rate can be observed along the drug concentrations, markedly for phenothiazines.

The inferential analysis suggested the concurrent lines (two intercepts) as the best fitted model for fluphenazine, chlorpromazine (at the 5\% significance level), and methotrimeprazine for Isolate 1 . The coincident lines were fitted to trifluoperazine in the same isolate (Table I). For Isolate 2 the coincident lines model was the best fit for all the phenothiazines, with the exception of methotrimeprazine. The concurrent lines model (two intercepts) was the best fit for this drug (Table II).

The $\mathrm{IC}_{50}$ estimates are presented in the natural logarithm form in Table III.
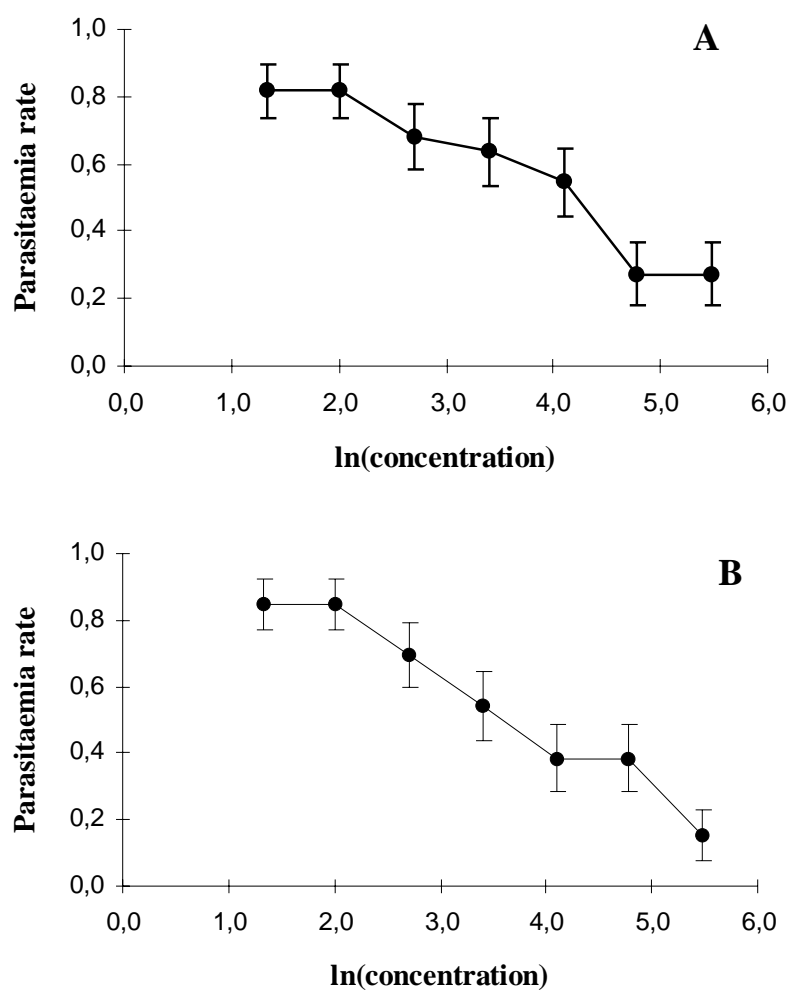

Fig. 2: ratios of the number of Plasmodium falciparum parasites in drug-treated cultures to the number in control cultures (parasitaemia rate) after exposure to chloroquine (A: Isolate 1; B: Isolate 2). 

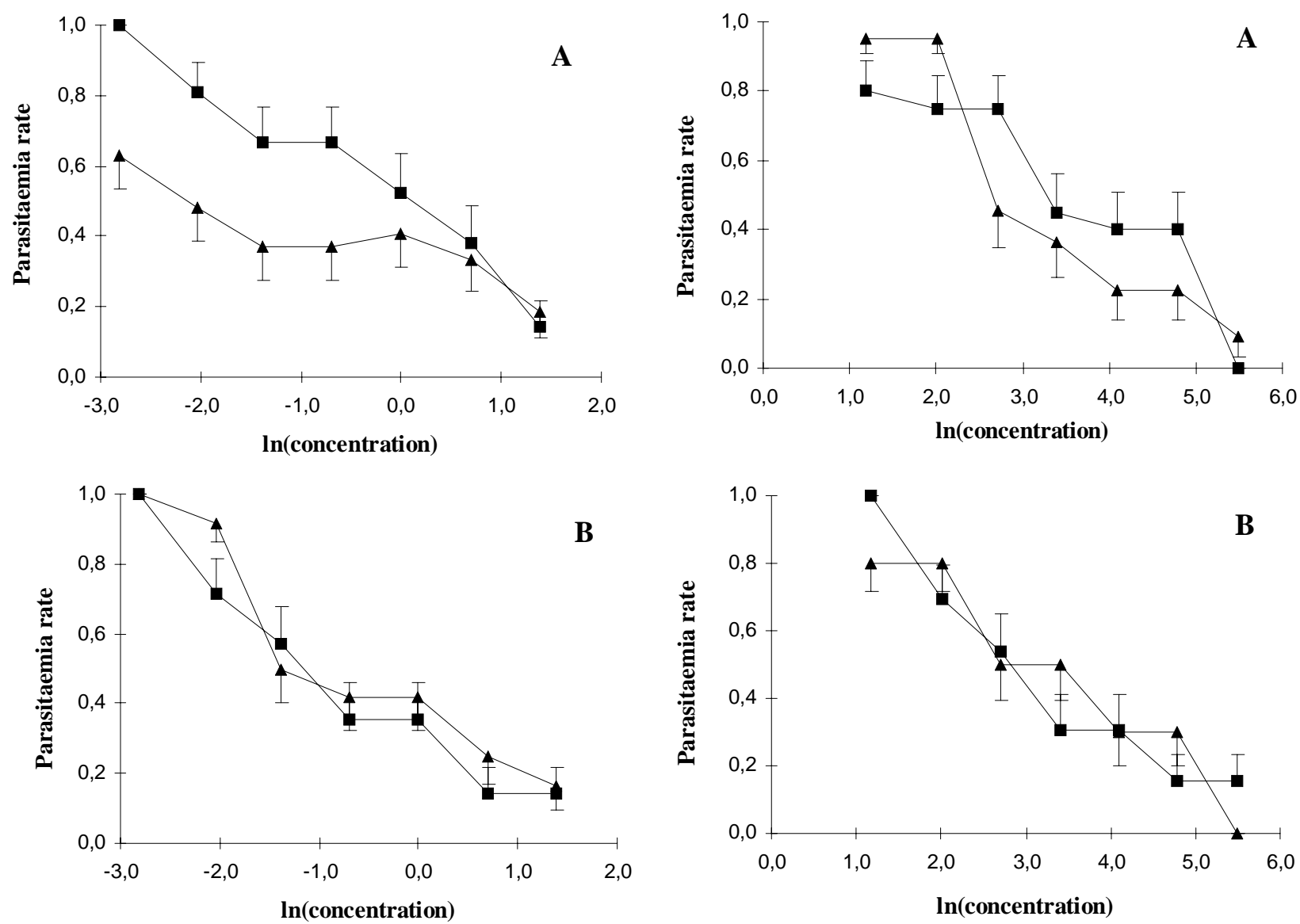

Fig. 3: ratios of the number of Plasmodium falciparum parasites in drug-treated cultures to the number in control cultures (parasitaemia rate) after exposure to fluphenazine $(\boldsymbol{\Delta})$ and fluphenazine plus

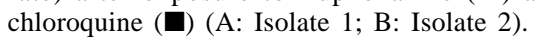

Fig. 4: ratios of the number of Plasmodium falciparum parasites in drug-treated cultures to the number in control cultures (parasitaemia rate) after exposure to chlorpromazine $(\boldsymbol{\Delta})$ and chlorpromazine

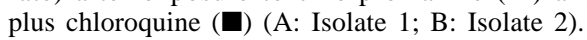

TABLE I

Fitted linear logistic model for the phenothiazine drugs and their combinations with chloroquine (Isolate 1, Sucen 198/94)

\begin{tabular}{|c|c|c|c|c|c|c|c|}
\hline Drug & Fitted model & $\begin{array}{l}\text { Goodness-of-fit } \\
\text { statistic }\end{array}$ & $\begin{array}{l}\text { Degrees } \\
\text { of freedom }\end{array}$ & P-value & $\begin{array}{c}\text { Likelihood } \\
\text { ratio statistic }\end{array}$ & $\begin{array}{l}\text { Degrees of } \\
\text { freedom }\end{array}$ & P-value \\
\hline \multirow[t]{4}{*}{ Fluphenazine } & Coincident lines & 33.182 & 12 & 0.001 & & & \\
\hline & Parallel lines & 17.612 & 11 & 0.091 & 15.570 & 1 & $<0.001$ \\
\hline & Concurrent lines (1 intercept) & 12.932 & 11 & 0.298 & 20.250 & 1 & $<0.001$ \\
\hline & Concurrent lines (2 intercepts) & 8.036 & 10 & 0.625 & 25.145 & 2 & 0.001 \\
\hline \multirow[t]{4}{*}{ Chlorpromazine } & Coincident lines & 24.346 & 11 & 0.011 & & & \\
\hline & Parallel lines & 23.679 & 10 & 0.008 & 0.667 & 1 & 0.414 \\
\hline & Concurrent lines ( 1 intercept) & 22.742 & 9 & 0.007 & 1.604 & 2 & 0.448 \\
\hline & Concurrent lines (2 intercepts) & 14.768 & 8 & 0.064 & 9.579 & 3 & 0.023 \\
\hline \multirow[t]{4}{*}{ Methotrimeprazine } & Coincident lines & 17.798 & 12 & 0.122 & & & \\
\hline & Parallel lines & 7.597 & 11 & 0.748 & 10.201 & 1 & 0.001 \\
\hline & Concurrent lines ( 1 intercept) & 12.117 & 11 & 0.355 & 5.681 & 1 & 0.017 \\
\hline & Concurrent lines ( 2 intercepts) & 4.290 & 10 & 0.933 & 13.508 & 2 & 0.001 \\
\hline \multirow[t]{4}{*}{ Trifluoperazine } & Coincident lines & 15.846 & 11 & 0.147 & & & \\
\hline & Parallel lines & 15.787 & 10 & 0.106 & 0.059 & 1 & 0.808 \\
\hline & Concurrent lines ( 1 intercept) & 13.138 & 9 & 0.156 & 2.708 & 2 & 0.258 \\
\hline & Concurrent lines (2 intercepts) & 12.189 & 8 & 0.143 & 3.657 & 3 & 0.301 \\
\hline
\end{tabular}



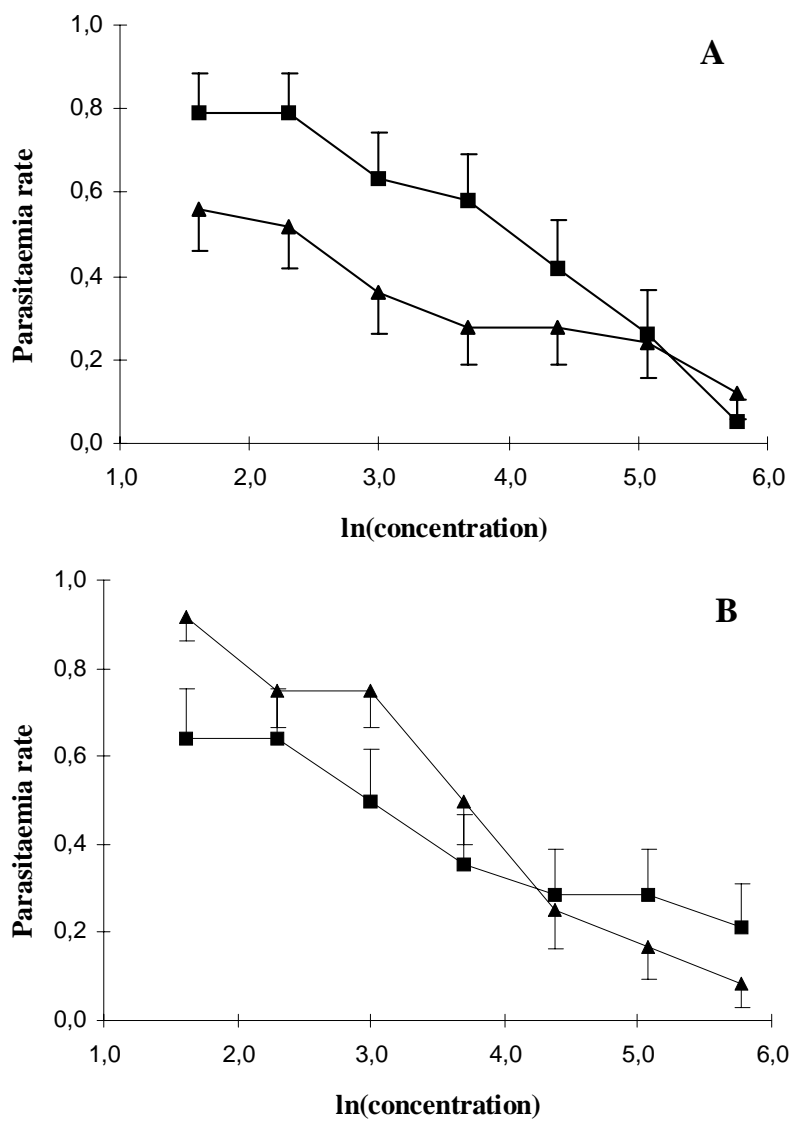

Fig. 5: ratios of the number of Plasmodium falciparum parasites in drug-treated cultures to the number in control cultures (parasitaemia rate) after exposure to methotrimeprazine $(\boldsymbol{\Delta})$ and metho-

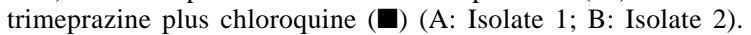
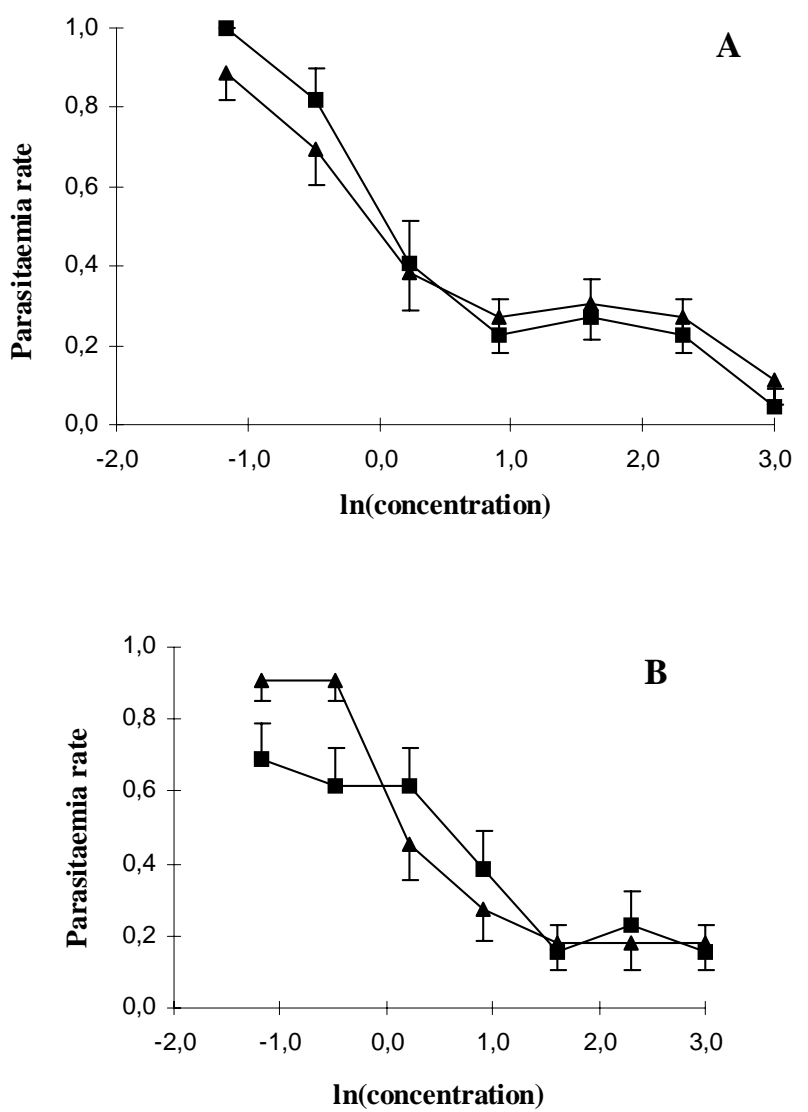

Fig. 6: ratios of the number of Plasmodium falciparum parasites in drug-treated cultures to the number in control cultures (parasitaemia rate) after exposure to trifluoperazine $(\boldsymbol{\Delta})$ and trifluoperazine plus

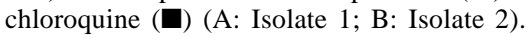

TABLE II

Fitted linear logistic model for the phenothiazine drugs and their combinations with chloroquine (Isolate 2, Sucen 206/94)

\begin{tabular}{|c|c|c|c|c|c|c|c|}
\hline Drug & Fitted model & $\begin{array}{l}\text { Goodness-of-fit } \\
\text { statistic }\end{array}$ & $\begin{array}{l}\text { Degrees } \\
\text { of freedom }\end{array}$ & P-value & $\begin{array}{c}\text { Likelihood } \\
\text { ratio statistic }\end{array}$ & $\begin{array}{l}\text { Degrees of } \\
\text { freedom }\end{array}$ & P-value \\
\hline \multirow[t]{4}{*}{ Fluphenazine } & Coincident lines & 12.491 & 12 & 0.407 & & & \\
\hline & Parallel lines & 11.705 & 11 & 0.386 & 0.786 & 1 & 0.375 \\
\hline & Concurrent lines (1intercept) & 12.311 & 11 & 0.341 & 0.180 & 1 & 0.671 \\
\hline & Concurrent lines ( 2 intercepts) & 11.703 & 10 & 0.305 & 0.788 & 2 & 0.674 \\
\hline \multirow[t]{4}{*}{ Chlorpromazine } & Coincident lines & 9.617 & 12 & 0.650 & & & \\
\hline & Parallel lines & 9.607 & 11 & 0.566 & 0.010 & 1 & 0.920 \\
\hline & Concurrent lines ( 1 intercept) & 9.568 & 11 & 0.570 & 0.049 & 1 & 0.825 \\
\hline & Concurrent lines ( 2 intercepts) & 9.474 & 10 & 0.488 & 0.143 & 2 & 0.931 \\
\hline \multirow[t]{4}{*}{ Methotrimeprazine } & Coincident lines & 7.723 & 12 & 0.806 & & & \\
\hline & Parallel lines & 6.609 & 11 & 0.830 & 1.114 & 1 & 0.291 \\
\hline & Concurrent lines ( 1 intercept) & 7.657 & 11 & 0.744 & 0.066 & 1 & 0.797 \\
\hline & Concurrent lines ( 2 intercepts) & 1.471 & 10 & 0.999 & 6.252 & 2 & 0.044 \\
\hline \multirow[t]{4}{*}{ Trifluoperazine } & Coincident lines & 9.446 & 12 & 0.664 & & & \\
\hline & Parallel lines & 9.173 & 11 & 0.606 & 0.273 & 1 & 0.601 \\
\hline & Concurrent lines ( 1 intercept) & 9.406 & 11 & 0.584 & 0.040 & 1 & 0.841 \\
\hline & Concurrent lines ( 2 intercepts) & 7.735 & 10 & 0.655 & 1.711 & 2 & 0.425 \\
\hline
\end{tabular}


TABLE III

Estimated median inhibitory concentrations $\left(\mathrm{IC}_{50}\right)$ of chloroquine, the phenothiazine drugs and the respective combinations on Plasmodium falciparum in vitro

\begin{tabular}{|c|c|c|c|c|}
\hline \multirow[b]{2}{*}{ Drug/Combination } & \multicolumn{2}{|c|}{ Isolate 1 (Sucen 198/94) } & \multicolumn{2}{|c|}{ Isolate 2 (Sucen 206/94) } \\
\hline & $\begin{array}{r}\mathrm{IC}_{50}{ }^{a} \\
(\mu \mathrm{g} / \mathrm{l})\end{array}$ & $\begin{array}{c}\text { Confidence interval } \\
(95 \%)\end{array}$ & $\begin{array}{r}\mathrm{IC}_{50}{ }^{a} \\
(\mu \mathrm{g} / \mathrm{l})\end{array}$ & $\begin{array}{c}\text { Confidence interval } \\
(95 \%)\end{array}$ \\
\hline Chloroquine & 3.96 & $3.42 ; 4.31$ & 3.72 & $3.13 ; 4.31$ \\
\hline Fluphenazine & -1.94 & $-3.03 ;-0.85$ & $-0.72^{b}$ & $-1.06 ;-0.38$ \\
\hline Chloroquine + Fluphenazine & -0.10 & $-0.52 ; 0.32$ & & \\
\hline Chlorpromazine & 2.96 & $1.33 ; 4.59$ & $3.11^{b}$ & $2.72 ; 3.50$ \\
\hline Chloroquine + Chlorpromazine & 3.75 & $0.68 ; 6.81$ & & \\
\hline Methotrimeprazine & 2.14 & $1.19 ; 3.08$ & 3.62 & $1.30 ; 5.94$ \\
\hline Chloroquine + Methotrimeprazine & 3.71 & $3.25 ; 4.17$ & 2.95 & $0.64 ; 5.27$ \\
\hline Trifluoperazine & $0.19^{b}$ & $-0.062 ; 0.44$ & $0.42^{b}$ & $-0.009 ; 0.85$ \\
\hline Chloroquine + Trifluoperazine & & & & \\
\hline
\end{tabular}

$a$ : $\log _{\mathrm{n}} 50 \%$ inhibitory concentration; $b$ : same values (coincident lines model)

\section{DISCUSSION}

Many hypotheses have been advanced to explain the $P$. falciparum resistance to chloroquine. The reversal of chloroquine resistance by verapamil suggested a similar mammalian tumor cells multidrug-resistant phenotype in malaria. Furthermore, many different drugs and compounds have been assayed for their modulating effect in restoring antimalarial drugs effectiveness (Ward \& Bray 2001).

In our study, a series of drugs reported as modulating agents in resistant malaria and/or neoplastic multidrug-resistant cell lines were evaluated in Brazilian chloroquine-resistant fresh isolates of $P$. falciparum. The in vitro microtechnique (Rieckmann et al. 1978) was chosen as it matches closely with scintillometric measurements (Le Bras et al. 1984), and it presents great feasibility in field studies (Yang et al. 1997, Philipps et al. 1998, Arez et al. 1999, Warsame et al. 1999). The chloroquine $\mathrm{IC}_{50}$ estimates indicated that the isolates were resistant, according to WHO statements (Bruce-Chwatt 1986). Moreover, these concentrations are among those reported in previous studies on chloroquine P. falciparum resistance reversal (Krogstad et al. 1987, Martin et al. 1987, Bitonti \& Mc Cann 1989, Basco \& Le Bras 1990, Kyle et al. 1990).

With the purpose of simulating therapeutic schedules, a particular drug combination was adopted. The intermediate concentration in the two-fold serial dilutions corresponded to the usual therapeutic concentration of the assessed modulating agent. A fixed concentration of chloroquine $(30 \mu \mathrm{g} / \mathrm{l})$ was employed in the combinations. This concentration is capable of clearance of parasitaemia in sensitive $P$. falciparum infections (Tracy \& Webster 1996). Once the modulating effect was observed, chloroquine would return its effectiveness. A fixed concentration of chloroquine was also used to determine the antimalarial response modification index throughout the combination of modulating agents (Kyle et al. 1990, Oduola et al. 1998).

This study reports the evaluation of the phenothiazine drugs: fluphenazine, chlorpromazine, metho- trimeprazine, and trifluoperazine. Other tricyclic compounds, e.g., desipramine, cyproheptadine, and their analogues (Bitonti et al. 1988, Basco \& Le Bras 1990, Peters et al. 1990, Basco et al. 1991) were early reported as modulating agents on resistant malaria. Previous studies with chlorpromazine, trifluoperazine and promethazine have also demonstrated the in vitro and in vivo reversal of chloroquine resistance (Kyle et al. 1990, 1993, Basco \& Le Bras 1992, Miki et al. 1992, Oduola et al. 1998).

However, different results were observed in our study. The phenothiazines drugs did not modulate chloroquine resistance. Similar behavior was observed for verapamil (Menezes et al. unpublished data), imipramine (Menezes et al. 1997) and most of the other modulating agents assessed. These results corroborated recent observations when Brazilian chloroquine-resistant strains demonstrated a lesser degree of susceptibility to verapamil when compared to strains from Africa and Southeast Asia (Mehlotra et al. 2001).

It is also important to note that, in our study, all the phenothiazine drugs demonstrated intrinsic antiplasmodial effects at concentrations inferior to those described as sub-inhibitory in modulating the antimalarial resistance (as example, $625 \mathrm{nM}$, that corresponds to $199.30 \mu \mathrm{g} / \mathrm{l}$, for chlorpromazine) (Kyle et al. 1990, Basco \& Le Bras 1992). However, in spite of the common phenothiazine chemical structure (Fig. 1), distinct behaviors were observed in the combinations with chloroquine. For Isolate 1, the concurrent lines model (two intercepts) was the best fit for methotrimeprazine, fluphenazine and chlorpromazine while the coincident lines model was the best model for trifluoperazine. The latter model was also the best fit for all drugs except methotrimeprazine, in the case of Isolate 2. The distinct fitted statistical lines models may be related to peculiarities of the isolates. To date, these results are most interesting.

Inhibition of falcipain and the interaction with heme moiety (ferriprotoporfyrin IX) have been associated to the antiplasmodial activity of phenothiazine compounds (Panijpan \& Kantakanit 1983, Domínguez et al. 1997). Dur- 
ing the intraerythrocytic stage, inside the food vacuole, specific parasite proteases, such as falcipain, degrade the host hemoglobin in order to generate amino acids for protein synthesis. The resulting heme is detoxified by a polymerization process to form the malarial pigment, hemozoin. Thus, inhibition of falcipain would precede the interference in the heme polymerization process, the most accepted hypothesis regarding the mechanism of chloroquine action (Padmanaban \& Rangarajan 2000).

Our results should be contemplated taking into account the phases in which chloroquine and phenothiazine compounds are believed to interfere with the Plasmodium hemoglobin metabolism. Inhibition of falcipain and/ or a stronger interaction of the phenothiazine drugs with heme moiety compared to that of chloroquine could be responsible for the predominant antiplasmodial effects of these compounds over chloroquine. This hypothesis may be supported by the coincident lines model. Conversely, the competition for the heme moiety could explain the concurrent lines model. In this situation, the addition of chloroquine caused an increase in the parasitaemia rate for most phenothiazine concentrations.

Although further assays are needed to check the proposed mechanistic hypothesis, we believe our findings are important to demonstrate the antiplasmodial effect of phenothiazine drugs at concentrations lower than those employed in anti-psychotic therapy, as observed by the estimated $\mathrm{IC}_{50}$ values. In addition, those concentrations showed to be lower than those previously related to antimalarial activity. Falcipain inhibition as well as the interaction with heme moiety (Panijpan \& Kantakanit 1983, Domínguez et al. 1997) and other antiplasmodial activities of phenothiazines, such as calmodulin antagonism (Scheibel et al. 1987), membrane stabilization (Kristiansen \& Jepsen 1985), disturbance in mitochondrial function (Geary et al. 1986) and the inhibition of glutathione reductase (Luond et al. 1998) were all observed in higher and, in general, toxic concentrations.

In resume, the results here presented corroborate previous findings in considering phenothiazine derivatives as interesting lead compounds in the design of new antimalarial agents (Vennerstrom et al.1995, Atamna et al. 1996, Domínguez et al. 1997).

\section{REFERENCES}

Arez AP, Snounou G, Pinho J, Sousa CA, Modiano D, Ribeiro H, Franco AS, Alves J, Rosario VE 1999. A clonal Plasmodium falciparum population in an isolated outbreak of malaria in the Republic of Cabo Verde. Parasitology 118: 347355.

Atamna H, Krugliak M, Shalmiev G, Deharo E, Pescarmona G, Ginsburg H 1996. Mode of antimalarial effect of methylene blue and some of its analogues on Plasmodium falciparum in culture and their inhibition of $P$. vinckei petteri and $P$. yoelii nigeriensis in vivo. Biochem Pharmacol 51: 693-700.

Basco LK, Le Bras J 1990. Reversal of chloroquine resistance with desipramine in isolates of Plasmodium falciparum from Central and West Africa. Trans R Soc Trop Med Hyg 84: 479-481.

Basco LK, Le Bras J 1992. In vitro activities of chloroquine in combination with chlorpromazine and prochlorperazine against isolates of Plasmodium falciparum. Antimicrob. Ag Chemother 36: 209-213.
Basco LK, Ringwald P, Le Bras J 1991. Chloroquine-potentiating action of antihistaminics in Plasmodium falciparum in vitro. Ann Trop Med Parasitol 85: 223-228.

Benet LZ, Øie S, Schwartz JB 1996. Design and optimization of dosage regimens pharmacokinetic data. In JG Hardman, LE Limbird, PB Molinoff, RW Ruddon, AG Gilmann (eds), Goodman \& Gilman's: the Pharmacological Basis of Therapeutics, 9th ed., Pergamon-Press, New York, p. 1707-1792.

Bitonti AJ, McCann PP 1989. Desipramine and cyproheptadine for reversal of chloroquine resistance in Plasmodium falciparum. Lancet 2: 1282-1283.

Bitonti AJ, Sjoerdsma A, Mccann PP, Kyle DE, Oduola AMJ, Rossan RN, Milhous WK, Davidson Jr DE 1988. Reversal of chloroquine resistance in malaria parasite Plasmodium falciparum by desipramine. Science 242: 1301-1303.

Breslow NE, Day NE 1980. Statistical Methods in Cancer Research. 1. The Analysis of Case Control Studies, International Agency for Research on Cancer, Lyon, $350 \mathrm{pp}$.

Bruce-Chwatt LJ 1986. Chemotherapy of Malaria, 2nd ed., WHO, Geneva, p. 211-233.

Clarke EC 1986. Isolation and Identification of Drugs in Pharmaceuticals, Body Fluids and Post-mortem Material, 2nd ed., Pharmaceutical Press, London, 1223 pp.

Collett D 1991. Modelling Binary Data, Chapman \& Hall, London, $369 \mathrm{pp}$.

Domínguez JN, López S, Charris J, Iarruso L, Lobo G, Semenov A, Olson JE, Rosenthal PJ 1997. Synthesis and antimalarial effects of phenothiazine inhibitors of a Plasmodium falciparum cysteine protease. J Med Chem 40: 2726-2732.

Geary TG, Divo AA, Jensen JB 1986. Effect of calmodulin inhibitors on viability and mitochondrial potential of Plasmodium falciparum in culture. Antimicrob Ag Chemother 30: 785-788.

Kristiansen JE, Jepsen S 1985. The susceptibility of Plasmodium falciparum in vitro to chlorpromazine and the stereoisomeric compounds cis(Z)- and trans(E)-clopenthixol. Acta Pathol Microb Immunol Scand (Section B) 93: 249-251.

Krogstad DJ, Gluzman IY, Kyle DE, Oduola AMJ, Martin SK, Milhous WK, Schlesinger PH 1987. Efflux of chloroquine from Plasmodium falciparum: mechanism of chloroquine resistance. Science 238: 1283-1285.

Kyle DE, Milhous WK, Rossan RN 1993. Reversal of Plasmodium falciparum resistance to chloroquine in Panamanian Aotus monkeys. Am J Trop Med Hyg 48: 126-133.

Kyle DE, Oduola AMJ, Martin SK, Milhous WK 1990. Plasmodium falciparum: modulation by calcium antagonists of resistance to chloroquine, desethylchloroquine, quinine, and quinidine in vitro. Trans $R$ Soc Trop Med Hyg 84: 474-478.

Le Bras J, Andrieu B, Hatin I, Savel J, Coulaud JP 1984. Plasmodium falciparum: interprétation du semi-microtest de sensibilité in vitro par incorporation de ${ }^{3} \mathrm{H}$-hypoxanthine. Pathol Biol 32: 463-466.

Luond RM, McKie JH, Douglas KT, Dascombe MJ, Vale J 1998. Inhibitors of glutathione reductase as potential antimalarial drugs. Kinetic cooperativity and effect of dimethyl sulphoxide on inhibiton kinetics. J Enzyme Inhib 13: 327345.

Martin SK, Oduola AMJ, Milhous WK 1987. Reversal of chloroquine resistance in Plasmodium falciparum by verapamil. Science 235: 899-901.

Mehlotra RK, Fujioka H, Roepe PD, Janneh O, Ursos LMB, Jacobs-Lorena V, Mcnamara DT, Bockarie MJ, Kazura JW, Kyle DE, Fidock DA, Zimmerman PA 2001. Evolution of a unique Plasmodium falciparum chloroquine-resistance phenotype in Papua New Guinea and South America. Proc Natl Acad Sci USA 98: 12689-12694. 
Menezes CMS, Kirchgatter K, Di Santi SMF, Savalli C, Monteiro FG, Paula GA, Ferreira EI 1997. Antimalarial effect in vitro and lack of modulating effect of desipramine and imipramine. Trans R Soc Trop Med Hyg 91: 697-700.

Miki A, Tanabe K, Nakayama T, Kiryon C, Ohsawa K 1992. Plasmodium chabaudi: association of reversal of chloroquine resistance with increased accumulation of chloroquine in resistant parasites. Exp Parasitol 74: 134-142.

Oduola AMJ, Sowunmi A, Milhous WK, Brewer TG, Kyle DE, Gerena L, Rossan RN, Salako LA, Schuster BG 1998. In vitro and in vivo reversal of chloroquine resistance in Plasmodium falciparum with promethazine. Am J Trop Med Hyg 58: 625-629.

Padmanaban G, Rangarajan PN 2000. Heme metabolism of Plasmodium is a major antimalarial target. Biochem Biophys Res Commun 268: 665-668.

Panijpan B, Kantakanit N 1983. Chlorpromazine enhances haemolysis induced by haemin. J Pharm Pharmacol 35: 473-475.

Peters W, Ekong R, Robinson BL, Warhurst DC, Xing-Qing P 1990. The chemotherapy of rodent malaria. XLV. Reversal of chloroquine resistance in rodent and human Plasmodium by antihistaminic agents. Ann Trop Med Parasitol 84: 541551.

Philipps J, Radloff PD, Wernsdorfer W, Kremsner PG 1998. Follow-up of the susceptibility of Plasmodium falciparum to antimalarials in Gabon. Am J Trop Med Hyg 58: 612-618.

Rieckmann KH, Sax LJ, Campbell GH, Mrema JE 1978. Drug sensitivity of Plasmodium falciparum. An in vitro microtechnique. Lancet I: 22-23.

Scheibel LW, Colombani PM, Hess AD, Aikawa M, Atkinson CT, Milhous WK 1987. Calcium and calmodulin antago- nists inhibit human malaria parasites (Plasmodium falciparum): implications for drug design. Proc Natl Acad Sci USA 84: 7310-7314.

Tracy JW, Webster Jr LT 1996. Drugs used in the chemotherapy of protozoa infections: malaria. In JG Hardman, LE Limbird, PB Molinoff, RW Ruddon, AG Gilmann (eds), Goodman \& Gilman's: the Pharmacological Basis of Therapeutics, 9th ed., Pergamon-Press, New York, p. 965-985.

Trager W, Jensen BB 1976. Human malaria parasites in continuous culture. Science 193: 673-675.

Vennerstrom JL, Makler MT, Angerhofer CCK, Williams JA 1995. Antimalarials dyes revisited: xanthenes, azines, oxazines, and thiazines. Antimicrob Ag Chemother 39: 26712677.

Warsame M, Kilimali AEB, Wernsdorfer WH, Lebbad M, Rutta AS, Ericsson O 1999. Resistance to chloroquine and sulfadoxine-pyrimethamine in Plasmodium falciparum in Muheza district, Tanzania. Trans R Soc Trop Med Hyg 93: 312-313.

Ward SA, Bray PG 2001. Is reversal of chloroquine ready for clinic? Lancet 357: 904.

Wellems TE, Plowe CV 2001. Chloroquine-resistant malaria. J Infect Dis 184: 770-776.

WHO-World Health Organization 2000. Malaria, a Global Crisis. Fact sheet 1. The problem, WHO 03/06/00. Available from: www.rbm.who.int

Yang HL, Liu DQ, Yang YM, Huang KG, Dong Y, Yang PF, Liao MZ, Zhang CY 1997. In vitro sensitivity of Plasmodium falciparum to eight antimalarials in China-Myanmar and China-Lao PDR border areas. South Asian J Trop Med Pub Health 28: 460-464. 
1040 In Vitro Phenothiazine Antimalarial Activity • Carla MS Menezes et al. 